\title{
ChemComm
}

\section{Tetra-cationic imidazoliumyl-substituted phosphorus-sulfur heterocycles from a cationic organophosphorus sulfide $\dagger$}

Cite this: Chem. Commun., 2016,
52, 2023

Received 30th September 2015

Accepted 17th November 2015

DOI: $10.1039 / c 5 c c 08182 c$

www.rsc.org/chemcomm

\author{
Florian D. Henne, ${ }^{a}$ Fabian A. Watt, ${ }^{a}$ Kai Schwedtmann, ${ }^{a}$ Felix Hennersdorf, ${ }^{a}$ \\ Malte Kokoschka ${ }^{\text {bc }}$ and Jan J. Weigand ${ }^{* a}$
}

The reaction of imidazoliumyl-substituted $P^{(I I I)}$ cations of type $\left[\mathrm{L}^{(\mathrm{R}, \mathrm{Me})} \mathrm{PCl}_{2}\right]^{+}\left(3 a, b^{+} ; \mathrm{L}^{\mathrm{R}, \mathrm{Me}}=\right.$ imidazolium-2-yl $\mathrm{a}: \mathrm{R}=\mathrm{Me}$; $\left.\mathrm{b}: \mathrm{R}=\mathrm{iPr}\right)$ with $\left(\mathrm{Me}_{3} \mathrm{Si}\right)_{2} \mathrm{~S}$ leads to the formation of tetra-cationic, eight-membered phosphorus sulfur heterocycles $\left[\mathrm{L}^{(\mathrm{R}, \mathrm{Me})} \mathrm{PS}\right]_{4}{ }^{4+}\left(9 a, b^{4+}\right)$, which can be explained by the tetramerization of the intermediately formed cationic phosphorus monosulfide $\left[\mathrm{L}^{(\mathrm{R}, \mathrm{Me})} \mathrm{PS}\right]^{+}\left(8 \mathrm{a}, \mathrm{b}^{+}\right)$. The $\mathrm{P}_{4} \mathrm{~S}_{4}$ ring adopts a crown conformation as observed for cyclo- $S_{8}$. The Lewis base DMAP (4-dimethylaminopyridine) initiates a deoligomerization- and dismutation reaction of $9 a, b^{4+}$ to give $\mathrm{P}^{(1)}$ centered cation $\left[\mathrm{L}^{(\mathrm{R}, \mathrm{Me})}{ }_{2} \mathrm{P}\right]^{+}$ $\left(12 \mathrm{a}, \mathrm{b}^{+}\right)$and phosphorus disulfide $\left[(\mathrm{DMAP})_{2} \mathrm{PS}_{2}\right]^{+}\left(14^{+}\right)$.

Organophosphorus-sulfur heterocycles with the general constitution (RPS $)_{n}(n=2-4)$ and phosphorus in the oxidation state + III remain scarce, since their main access is from the reaction of a dichlorophosphane $\mathrm{RPCl}_{2}(\mathrm{R}=$ Aryl $)$ and a source of sulfide $\left(\mathrm{S}^{2-} ;\right.$ e.g. $\mathrm{M}_{2} \mathrm{~S}(\mathrm{M}=\mathrm{Li}$, $\mathrm{Na})$ or $\left.\left(\mathrm{Me}_{3} \mathrm{Si}\right)_{2} \mathrm{~S}\right)$. ${ }^{1}$ The formation of these compounds can formally be viewed as a combination of divalent RP: and S: units to give monomeric phosphorus mono-sulfides such as $\mathbf{1}$, which then can either yield oligomerization products (Fig. 1; path I) or ylidylphosphorus sulfide $2 \mathrm{a}$ (path II). ${ }^{1} \mathbf{2 a}$ represents a rare example of a stable and structurally confirmed monomeric ylidylphosphorus monosulfide. Its stability is rationalized by a high contribution of the zwitterionic resonance formula $2 \mathbf{b}$ (path $\mathbf{I I}$ ). ${ }^{2}$ Aiming at the synthesis of new cationic phosphorus species, we are investigating reactions of imidazoliumyl-substituted P-centered cations such as $\left.\left[\mathrm{L}^{(\mathrm{R}, \mathrm{R} /}\right) \mathrm{PCl}_{2}\right]^{+} 3^{+}$ $\left(\mathrm{L}^{\mathrm{R}, \mathrm{Me}}=\text { imidazolium-2-yl, } \mathrm{R}=\text { Aryl, Alkyl; } \mathrm{R}^{\prime}=\mathrm{H}, \mathrm{Me}, \mathrm{Cl}\right)^{3}$ towards substitution $^{3,4}$ (e.g. $\left.\mathbf{4}^{+}, 5^{+}\right)$, coordination, ${ }^{5}$ oxidation $^{6}$ or reduction ${ }^{7}$

\footnotetext{
${ }^{a}$ Department of Chemistry and Food Chemistry, Technische Universität Dresden, 01062 Dresden, Germany. E-mail: jan.weigand@tu-dresden.de

${ }^{b}$ Department of Computational Chemistry, Academy of Sciences of the Czech Republic, 16610 Praha 6, Czech Republic

${ }^{c}$ Department of Physical Chemistry, Palacky University, 77146 Olomouc,

Czech Republic

$\dagger$ Electronic supplementary information (ESI) available: For detailed experimental procedures and characterization details of new compounds, NMR spectra, crystallographic details and computational data. CCDC 1424341-1424343 and 1426199. For ESI and crystallographic data in CIF or other electronic format see DOI: $10.1039 / \mathrm{c} 5 \mathrm{cc} 08182 \mathrm{c}$
}
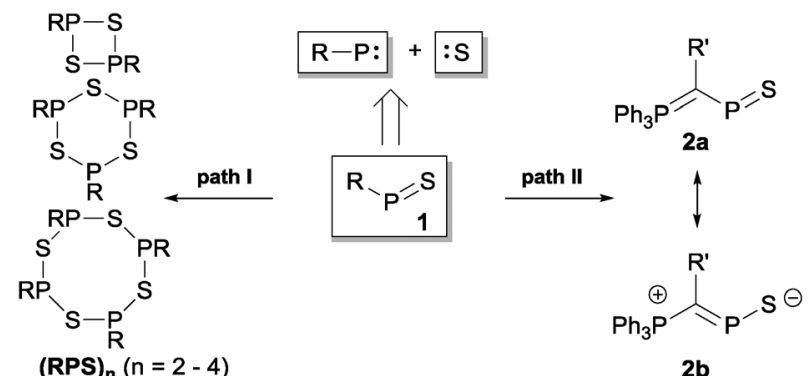

Fig. 1 Formation of oligomeric phosphorus sulfides (RPS) $n(n=2-4$; $\mathrm{R}=$ Aryl, $\mathrm{R}^{\prime}=$ Alkyl; path I) and phosphorus monosulfide $\mathbf{2 a , b}$ (path II).

(e.g. $\left.6^{+}, 7^{+}\right)$and successfully isolated a series of novel cationic derivatives with intriguing bonding motives (Fig. 2). In this contribution we present the results of the attempted preparation of the imidazoliumyl-substituted $\left[\mathrm{L}^{(\mathrm{R}, \mathrm{Me})} \mathrm{PS}\right]^{+}$cations $\mathbf{8 a}, \mathbf{b}^{+}(\mathrm{a}: \mathrm{R}=\mathrm{Me}$; b: $\mathrm{R}=\mathrm{iPr}$ ) from the reaction of $\mathbf{3 a}, \mathbf{b}^{+}$with $\left(\mathrm{Me}_{3} \mathrm{Si}\right)_{2} \mathrm{~S}$ and the respective oligomerization to tetra-cations $\mathbf{9 a}, \mathbf{b}^{\mathbf{4 +}}$ which can be isolated as triflate salts (Scheme 1). Compounds $\mathbf{3 a} \mathbf{a}, \mathbf{b}[\mathrm{OTf}]$ (ref. 3) were reacted with $1 \mathrm{eq}$. $\left(\mathrm{Me}_{3} \mathrm{Si}\right)_{2} \mathrm{~S}$ in fluorobenzene for $5 \mathrm{~h}$ at ambient temperature, accompanied by the formation of colorless precipitates. After workup, compounds $\mathbf{9 a}, \mathbf{b}[\mathrm{OTf}]_{4}$ were isolated in excellent yields (>90\%; Scheme 1). The ${ }^{31} \mathrm{P}\left\{{ }^{1} \mathrm{H}\right\}$ NMR spectra of the dissolved compounds in $\mathrm{d}_{3}-\mathrm{MeCN}$ display one major resonance next to a

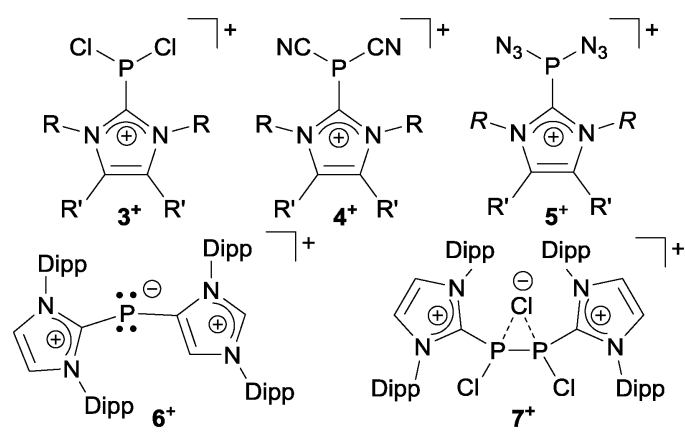

Fig. 2 Selected P-centered cations $\mathbf{3}-\mathbf{7}^{+}$featuring imidazoliumyl-substituents (Dipp = 2,6-diisopropylphenyl). 


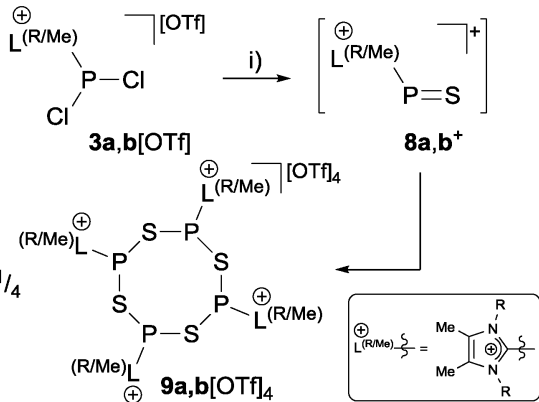

Scheme 1 Preparation of tetrameric imidazoliumyl-substituted phosphorus-sulfur heterocycles $\mathbf{9 a , b}[\mathrm{OTf}]_{4}$ from the intermediately formed cation $\mathbf{8 a}, \mathbf{b}^{+}(\mathrm{a}: \mathrm{R}=\mathrm{Me}$; b: $\mathrm{R}=\mathrm{iPr})$; (i) $+\left(\mathrm{Me}_{3} \mathrm{Si}\right)_{2} \mathrm{~S}, \mathrm{C}_{6} \mathrm{H}_{5} \mathrm{~F}, \mathrm{rt},-2 \mathrm{Me}_{3} \mathrm{SiCl}$.

minor singlet in the typical region of tri-coordinate phosphorus derivatives $\left(\mathbf{9 a}^{\mathbf{4}+}: \delta(\mathrm{P})_{\text {major } / \text { minor }}=48.2 \mathrm{ppm} / 48.0 \mathrm{ppm} ; \mathbf{9 b}^{\mathbf{4 +}}\right.$ : $\left.\delta(\mathrm{P})_{\text {major } / \text { minor }}=50.5 \mathrm{ppm} / 50.3\right)$ indicating the oligomerization of the intermediately formed cationic phosphorus monosulfide $\mathbf{8 a}, \mathbf{b}^{+}$. However, no evidence for the formation of other ring sizes was found, showing a high selectivity of the oligomerization process. It can be assumed that, under these conditions, the formation of the $\mathrm{P}_{4} \mathrm{~S}_{4}$ ring is thermodynamically (considering ring strain and steric effects) favored. The variable-temperature (VT) ${ }^{31} \mathrm{P}$ NMR spectra for $\mathbf{9 b}[\mathrm{OTf}]_{4}$ are depicted in Fig. 3a, evidencing a dynamic behavior and the presence of two highly symmetric conformational isomers (crown $\left(C_{4 v}\right)$ vs. boat-chair $\left(C_{\mathrm{s}}\right)$ conformer) of the $\mathrm{P}_{4} \mathrm{~S}_{4}$ ring in solution (Scheme 2). A significant broadening of the two resonances upon
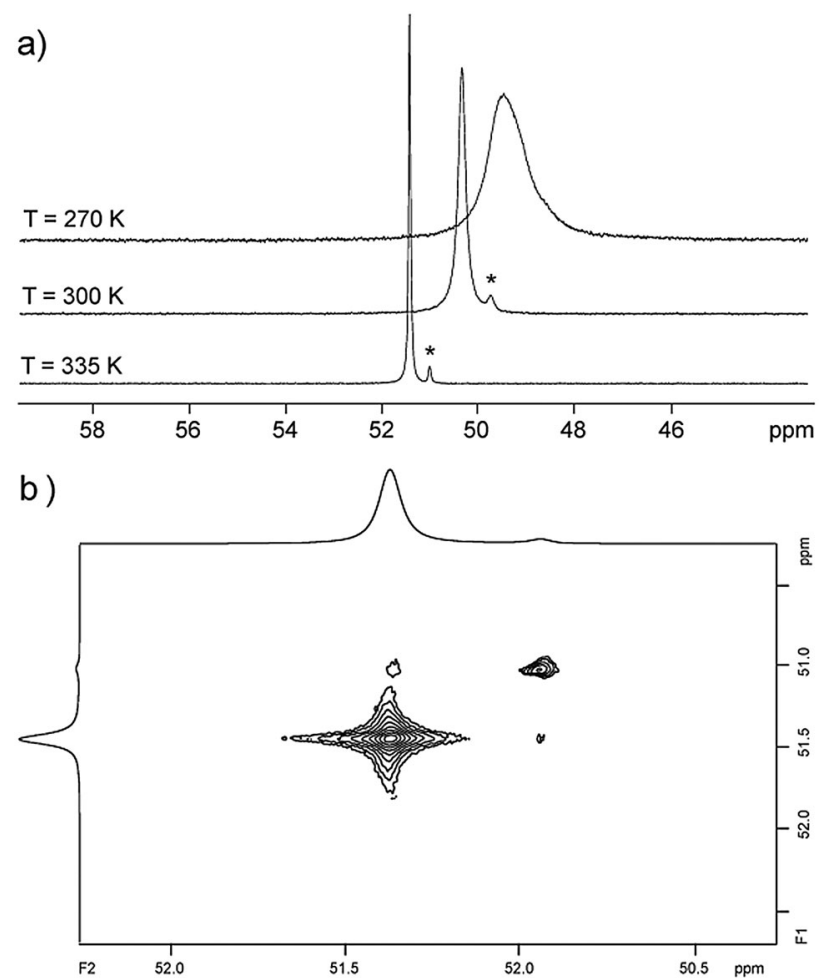

Fig. 3 (a) $V T{ }^{31} \mathrm{P}$ NMR spectra of $9 \mathbf{b}[\mathrm{OTf}]_{4}$ recorded in $\mathrm{CD}_{3} \mathrm{CN}$ (see ESI $\dagger$ ) * indicates minor amounts of the conformational isomer of $9 \mathbf{b}^{+}$; (b) ${ }^{31} \mathrm{P}$ EXSY NMR spectrum of $\mathbf{9 b}[\mathrm{OTf}]_{4}$ recorded at $335 \mathrm{~K}$ with a mixing time of $t_{\mathrm{m}}=0.55 \mathrm{~s}$.

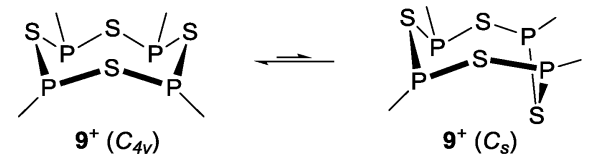

Scheme 2 Interconversion process of cations $\mathbf{9 a}, \mathbf{b}^{\mathbf{4 +}}$ from the conformational isomer with crown shape $\left(C_{4 v}\right)$ to the boat-chair $\left(C_{s}\right)$ conformer without considering the imidazoliumyl substituents.

cooling is observed. The VT ${ }^{1} \mathrm{H}$ NMR spectra also show additional dynamic behavior of the iPr-groups. We thus confirmed the existence of two conformational isomers independently by ${ }^{31} \mathrm{P}$ EXSY NMR experiments (Fig. 3b), although quantitative accuracy (to determine kinetic processes or exchange rates) was limited by the narrow temperature range in which useful spectra could be measured. The ${ }^{31} \mathrm{P}$ EXSY NMR experiments suggest exchange of two conformers in which one of the sulfur-bridges reversibly changes its relative position, giving either the approximate $C_{4 \mathrm{v}}$ or $C_{\mathrm{s}}$ symmetric cations $\mathbf{9 a}, \mathbf{b}^{\mathbf{4 +}}$ (Scheme 2). The cross peaks in the 2D spectrum demonstrate the exchange between the two symmetric conformers in solution, consistent with the observation of singlet resonances as expected for an $A_{4}$ spin-system for both isomers.

Satisfactory crystal structure analyses could be performed confirming the formation of the suggested eight-membered organophosphorus-sulfur heterocycles (Fig. 4). In the case of compound $\mathbf{9 b}[\mathrm{OTf}]_{4}$ the refinement of the X-ray data confirmed the crown-shaped $\mathrm{P}_{4} \mathrm{~S}_{4}$ moiety, similarly to cation $\mathbf{9 a ^ { 4 + }}$, however, due to severe disorder caused by alternating ring orientation full refinement was only possible after treatment by an appropriate disordered model. ${ }^{8}$ The $\mathrm{P}^{\mathrm{III}}-\mathrm{S}$ bond lengths (av. $2.129 \AA$ ) in $\mathbf{9 a}^{\mathbf{4 +}}$ are in the typical range for $\mathrm{P}^{\mathrm{III}}$-S single bonds and compare well with those reported by Sheldrick et al. for the neutral derivative (MesPS) (av. $2.117 \AA$ 和 Mes = 2,4,6-trimethylphenyl). ${ }^{1 b}$ The pyramidalization of the $\mathrm{P}$ atoms, as well as the lengths of the C-P bonds (av. $1.817 \AA$ ), together with the internal angle N1-C1-N2 of the imidazoliumyl moieties $\left(\mathbf{9 a}^{\mathbf{4}^{+}} \text {: av. } 106.9^{\circ} \text { vs. } \sim 101^{\circ} \text { in } \mathrm{NHCs}\right)^{9}$ are in agreement with the ability of the imidazoliumyl fragment to (a) delocalize the positive charge, (b) reduce the nucleophilicity of a directly bonded $\mathrm{P}$ atom and thus may account for the stability of these cations. ${ }^{5,10,11}$

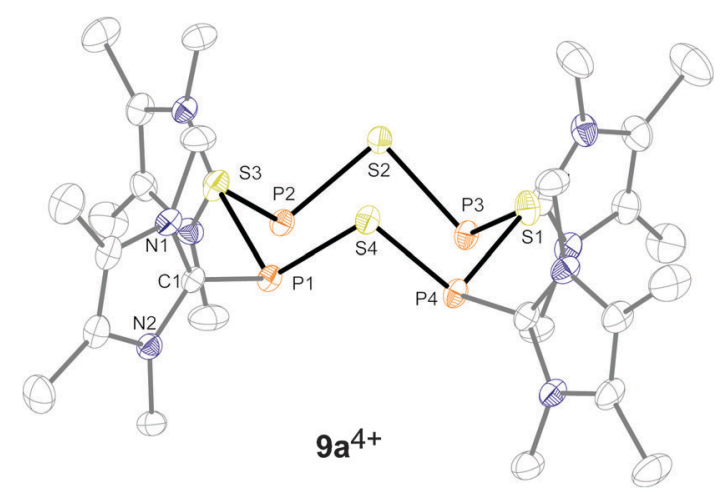

Fig. 4 Molecular structure of tetracation $\mathbf{9} a^{4+}$ in $\mathbf{9 a}[\mathrm{OTf}]_{4}$. All hydrogen atoms and triflate anions are omitted for clarity. Selected bond lengths in $\AA$ and angles in ${ }^{\circ}$ : P1-S1 2.1306(9), P1-S4 2.1364(9), P2-S1 2.1234(9), P1-C1 1.820(3), S1-P1-S4 101.99(4), S1-P1-C1 99.31(8), S4-P1-C1 101.26(9), N1-C1-N2 101.26(9). 


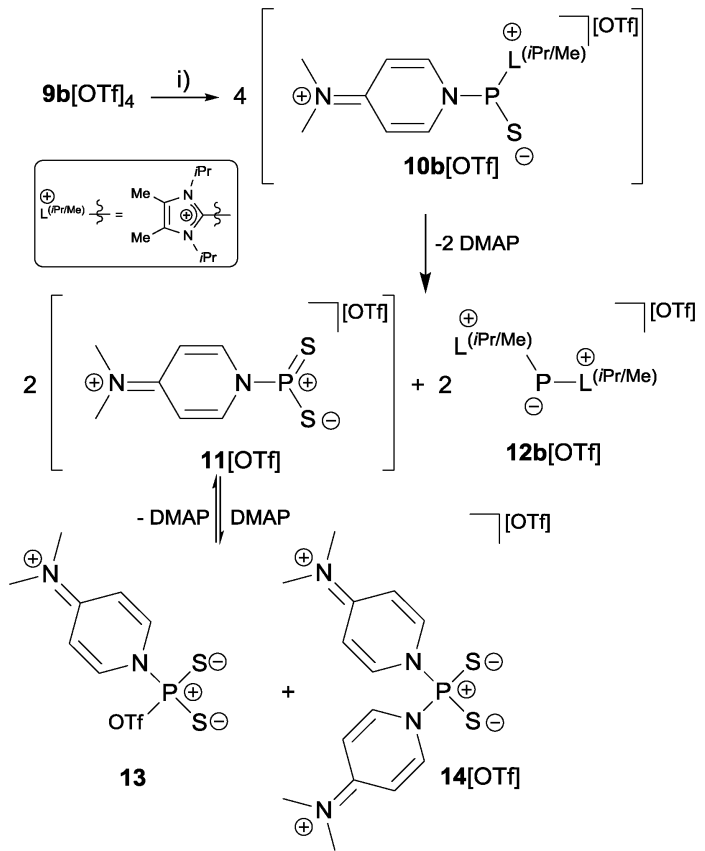

Scheme 3 Deoligomerization of $\mathbf{9 b}[\mathrm{OTf}]_{4}$ with DMAP and proposed intermediates; (i) +4 DMAP, MeCN, rt.

To confirm that the formation of tetracations $\mathbf{9 a}, \mathbf{b}^{\mathbf{4 +}}$ proceeds via monomeric phosphorus mono-sulfides $\mathbf{8 a}, \mathbf{b}^{+}$, we reacted $\mathbf{9 a}, \mathbf{b}[\mathrm{OTf}]_{4}$ with DMAP in MeCN, since this Lewis base has been widely used to stabilize low-coordinate phosphorus species. ${ }^{12}$ The $\sigma$-donor strength of DMAP should be high enough to deoligomerize tetracations $9 \mathbf{a}, \mathbf{b}^{\mathbf{4 +}}$ to cations $\mathbf{1 0 a}, \mathbf{b}^{+}$which represent DMAP adducts of the elusive cations $\mathbf{8 a}, \mathbf{b}^{+}$(Scheme 3). The reaction of 4 equivalents DMAP in $\mathrm{MeCN}$ proceeds comparably clean with $\mathbf{9 b}[\mathrm{OTf}]_{4}$ at ambient temperature giving pale-yellow solutions. The ${ }^{31} \mathrm{P}\left\{{ }^{1} \mathrm{H}\right\}$ NMR spectra of the reaction mixture of $\mathbf{9 b}[\mathrm{OTf}]_{4}$ and DMAP after reaction times of $10 \mathrm{~min}$ to $7 \mathrm{~d}$ are depicted in Fig. 5. After $10 \mathrm{~min}$ a broad resonance at $\delta(\mathrm{P})=147.1 \mathrm{ppm}$ is observed which splits into 2 singlets at low temperature $(\delta(\mathrm{P})=140.3 \mathrm{ppm}$ and $\delta(\mathrm{P})=144.4 \mathrm{ppm} ; 253 \mathrm{~K})$. We believe that the splitting of the resonances results from two rotational isomers caused by a restricted rotation of the iPr groups at low temperature. ${ }^{8,13}$ From the distinctive chemical shift a dimeric derivative with tetra-coordinate phosphorus atoms

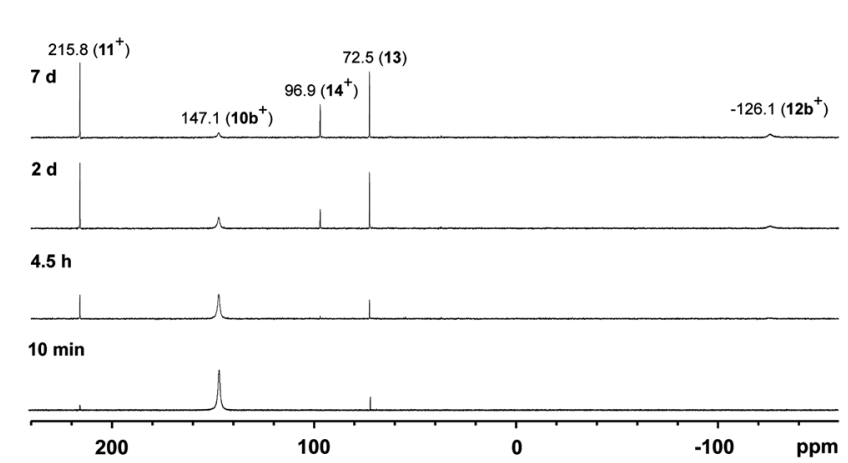

Fig. $5{ }^{31} P\left\{{ }^{1} H\right\}$ NMR spectra of the 1:4 reaction of $\mathbf{9 b}[\mathrm{OTf}]_{4}$ and DMAP in $\mathrm{CD}_{3} \mathrm{CN}$ showing the scrambling reaction to cations $11^{+}, 12 \mathbf{b}^{+}, 14^{+}$and adduct 13 . $\left(c f .\left[\left(\mathrm{Et}_{2} \mathrm{~N}\right)_{2} \mathrm{PS}_{2}\right]\left[\mathrm{AlCl}_{4}\right]_{2}: \delta(\mathrm{P})=21.0 \mathrm{ppm}\right)^{14}$ can be excluded and we thus propose the formation of DMAP adduct $\mathbf{1 0 b}^{+}$which is also supported by our NMR investigation. ${ }^{8}$ We were not able to isolate $\mathbf{1 0 b}[\mathrm{OTf}]$, however, we assume that cation $\mathbf{1 0 b}^{+}$readily dismutates to cations $\mathbf{1 1}^{+}(\delta(\mathrm{P})=215.8 \mathrm{ppm})$ and $\mathbf{1 2 b}^{+}(\delta(\mathrm{P})=-126.1 \mathrm{ppm})$ via an intermolecular scrambling reaction, i.e. an intermolecular exchange of imidazolium-2-yl and sulfur substituents. Related exchange reactions were discussed for the DMAP induced disproportionation of $\mathrm{POCl}_{3}{ }^{15}$ and scrambling reactions of imidazoliumylsubstituted $\left[\mathrm{L}^{(\mathrm{Me}, \mathrm{Me})} \mathrm{PCl}_{2}\right]^{+}$cations. ${ }^{4} \mathrm{P}^{\mathrm{I}}$ centered cation $\mathbf{1 3 \mathbf { b } ^ { + }}$ $(\delta(\mathrm{P})=-126.1 \mathrm{ppm})$ was recently reported by Macdonald et al. and unambiguously confirmed by its characteristic chemical shift (cf. lit: $\delta(\mathrm{P})=-124.2 \mathrm{ppm}, \mathrm{CD}_{2} \mathrm{Cl}_{2}$ ). ${ }^{16}$ Cations of type $12 \mathrm{a}^{+}$are also known and reported by Schmidpeter et al. as ylidylphosphorusdisulfide containing a tri-coordinate $\mathrm{R}-\mathrm{PS}_{2}$ moiety. For these types of compounds the chemical shift strongly depends on the nature of the supporting substituent $\mathrm{R}$ and is typically observed in the range of $\delta(\mathrm{P})=170-240 \mathrm{ppm}\left(c f . \mathrm{Ph}_{3} \mathrm{PCMe} \mathrm{PS}_{2}: \delta(\mathrm{P})_{\mathrm{PS}_{2}}=243.4 \mathrm{ppm}\right.$, $\mathrm{d}_{8}$-THF). ${ }^{2}$ In an equilibrium reaction of cation $\mathbf{1 1}^{+}$with the triflate anion the formation of $\mathbf{1 3}$ is explained and supported by the pronounced upfield shifted triplet resonance due to the coupling to the ortho-protons of the DMAP ligand (eqn (1); $\delta(\mathrm{P})=72.5 \mathrm{ppm}$, triplet, ${ }^{3} J_{\mathrm{PH}}=9.0 \mathrm{~Hz}$; $c f$. $\mathrm{PyPS}_{2} \mathrm{Br}: \delta(\mathrm{P})=65.5 \mathrm{ppm}, \mathrm{Py}=$ pyridine; $\mathrm{d}_{3}$-MeCN). ${ }^{17}$ The formation of cation $\mathbf{1 4}^{+}$results either from the equilibrium reaction of $\mathbf{1 1}^{+}$(eqn (2)) or $\mathbf{1 3}$ (eqn (3)) with DMAP which is liberated during the dismutation of cation $\mathbf{1 0 b}^{+}$(Scheme 3). The ${ }^{31} \mathrm{P}$ NMR spectrum displays a quintet resonance which is indicative for the presence of two DMAP substituents consistent with the $C_{2 \mathrm{v}}$ symmetry of cation $14^{+}\left(\delta(\mathrm{P})=96.9 \mathrm{ppm} ; c f .\left[\mathrm{Py}_{2} \mathrm{PS}_{2}\right]^{+}\right.$: $\delta(\mathrm{P})=104.7 \mathrm{ppm}$, quintet, ${ }^{3} J_{\mathrm{PH}}=9.6 \mathrm{~Hz} ; \mathrm{Py}=$ pyridine; $\left.\mathrm{d}_{3}-\mathrm{MeCN}\right)$. Similar equilibria and cations have been observed by Meisel $e t$ al. who reported on the pyridine (Py) stabilized phosphorus disulfide $\left[\mathrm{Py}_{2} \mathrm{PS}_{2}\right]^{+}$cation. ${ }^{18}$ Two crystalline polymorphs of $14[\mathrm{OTf}]$ were obtained after layering the reaction mixtures with $\mathrm{Et}_{2} \mathrm{O}$ (Fig. 6). ${ }^{19}$ The obtained structural parameters compare well with those reported for the related pyridine cation $\left[\mathrm{Py}_{2} \mathrm{PS}_{2}\right]^{+}$by Meisel et al. ${ }^{18}$

$$
\begin{gathered}
11[\mathrm{OTf}] \rightleftharpoons 13 \\
11[\mathrm{OTf}]+\mathrm{DMAP} \rightleftharpoons 14[\mathrm{OTf}] \\
13+\mathrm{DMAP} \rightleftharpoons 14[\mathrm{OTf}]
\end{gathered}
$$

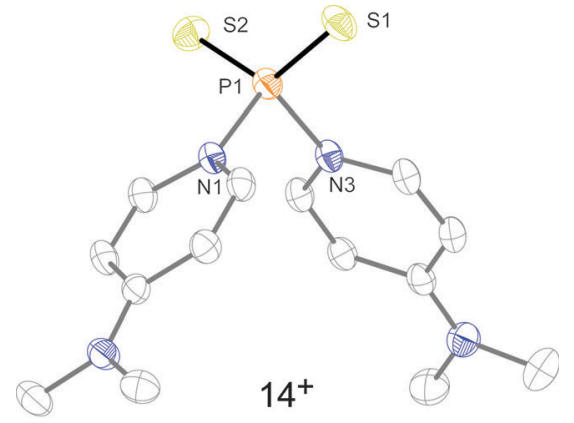

Fig. 6 Molecular structure of $14^{+}$in 14 [OTf]. All hydrogen atoms and the triflate anion are omitted for clarity. Selected bond lengths in $\AA$ and angles in $^{\circ}$ : P1-S1 1.9309(8), P1-S2 1.9321(8), P1-N1 1.782(2), P1-N2 1.798(2), S1-P1-S2 124.09(4), N1-P1-N2 96.77(8), S-P1-N av. 108.14. 


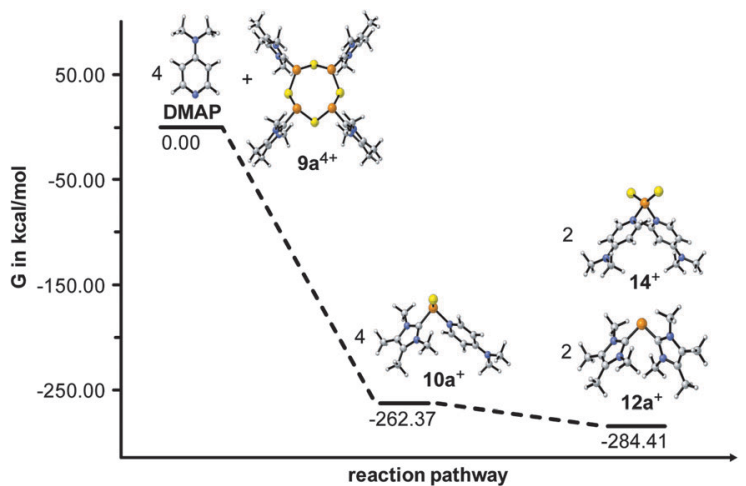

Fig. 7 Gibbs free energy in kcal $\mathrm{mol}^{-1}$ of the observed and proposed phosphorus species.

In order to confirm our findings and support the suggested dismutation, quantum chemical calculations have been performed from the reaction of $\mathbf{9 a ^ { 4 + }}$ with 4 eq. DMAP to derive geometry and Gibbs free energy of the involved species as well as the suggested reaction intermediate $\mathbf{1 0 a}^{+} .^{20}$ The density functional theory (DFT) hybrid model $\mathrm{B}^{2} \mathrm{LYP}^{21}$ was used in combination with Grimme's atom-pairwise dispersion correction (D3). ${ }^{22}$ Fig. 7 illustrates the Gibbs free energy $\Delta G$ of educts $\left(\mathbf{9 a}^{\mathbf{4}}\right.$, DMAP), products $\left(\mathbf{1 2 b}^{+}, \mathbf{1 4}^{+}\right)$and the proposed intermediate $\left(\mathbf{1 0 a}^{+}\right)$calculated at the B3LYP-D3/def-SVP level of theory. The whole reaction pathway is thermodynamically favored $\left(\Delta G=-284.4 \mathrm{kcal} \mathrm{mol}^{-1}\right)$. The proposed reaction intermediate $\mathbf{1 0 a}^{+}$is energetically less favorable by $22 \mathrm{kcal} \mathrm{mol}^{-1}$ compared to the final products, but $262 \mathrm{kcal} \mathrm{mol}^{-1}$ lower in energy than the educt molecules $\left(\Delta G=-262.4 \mathrm{kcal} \mathrm{mol}^{-1}\right)$. This observation is perfectly in line with the assumption of $\mathbf{1 0 a}^{+}$being the main reaction intermediate.

In summary, we reported on the oligomerization reaction of cationic phosphorus monosulfides $\mathbf{8 a}, \mathbf{b}^{+}$which were formed in situ from the reaction of $\left[\mathrm{L}^{(\mathrm{R}, \mathrm{Me})} \mathrm{PCl}_{2}\right]^{+}$cations $3 \mathbf{a}, \mathbf{b}^{+}\left(\mathrm{L}^{\mathrm{R}, \mathrm{Me}}=\right.$ imidazolium-2-yl a: $\mathrm{R}=\mathrm{Me}$; b: $\mathrm{R}=\mathrm{iPr})$ and $\left(\mathrm{Me}_{3} \mathrm{Si}\right)_{2} \mathrm{~S}$. The obtained tetra-cationic, eight-membered phosphorus-sulfur heterocycles $\left[\mathrm{L}^{(\mathrm{R}, \mathrm{Me})} \mathrm{PS}\right]_{4}{ }^{4+} \mathbf{9 a}, \mathbf{b}^{4+}$ primarily exist as crown conformers similar to cyclo- $\mathrm{S}_{8}$, however, the boat-chair $\left(C_{\mathrm{s}}\right)$ conformers of the $\mathrm{P}_{4} \mathrm{~S}_{4}$ rings also exist in solution according to $2 \mathrm{D}$-EXSY ${ }^{31} \mathrm{P}$ NMR experiments. Cations $\mathbf{9 a}, \mathbf{b}^{\mathbf{4 +}}$ can be deoligomerized by DMAP to yield adducts $\mathbf{1 0 a}, \mathbf{b}^{+}$of the elusive cations $\mathbf{8 a}, \mathbf{b}^{+}$. Subsequent dismutation of 10a, $\mathbf{b}^{+}$gives cations $\left[\mathrm{L}^{(\mathrm{R}, \mathrm{Me})}{ }_{2} \mathrm{P}\right]^{+}\left(\mathbf{1 2 a}, \mathbf{b}^{+}\right)$and $\left[(\mathrm{DMAP})_{2} \mathrm{PS}_{2}\right]^{+}\left(\mathbf{1 4}^{+}\right)$as final products. The suggested reaction pathway was supported by DFT calculations.

This work was supported by the Fonds der Chemischen Industrie (FCI, Kekule scholarship for F. H.), the German Science Foundation (DFG, WE 4621/2-1) and the ERC (SynPhos 307616). Financial support of $\mathrm{M}$. K. by a POSTUP ${ }^{2}$ grant (European social fund in the Czech Republic, European Union, Czech ministry of education and sports, operational program for the advancement of the competitive capacity) is gratefully acknowledged (CZ.1.07/2.3.00/30.0041). We thank the Center for Information Services and High Performance Computing (ZIH) for the generous allocation of computation time.

\section{References}

1 (a) T. Chivers and I. Manners, Inorganic Rings and Polymers of the p-Block Elements, RSC Publishing, 2009; (b) C. Lensch and G. M. Sheldrick, J. Chem. Soc., Dalton Trans., 1984, 2855-2857; (c) B. Cetinkaya, P. B. Hitchcock, M. F. Lappert, A. J. Thorne and H. Goldwhite, J. Chem. Soc., Chem. Commun., 1982, 691-693; (d) M. Baudler, D. Koch, T. Vakratsas, E. Tolls and K. Kipker, Z. Anorg. Allg. Chem., 1975, 413, 239-251.

2 G. Jochem, K. Karaghiosoff, S. Plank, S. Dick and A. Schmidpeter, Chem. Ber., 1995, 128, 1207-1219.

3 J. J. Weigand, K.-O. Feldmann and F. D. Henne, J. Am. Chem. Soc., 2010, 132, 16321-16323.

4 F. D. Henne, A. T. Dickschat, F. Hennersdorf, K. O. Feldmann and J. J. Weigand, Inorg. Chem., 2015, 54, 6849-6861.

5 K. Schwedtmann, M. H. Holthausen, K.-O. Feldmann and J. J. Weigand, Angew. Chem., Int. Ed., 2013, 52, 14204-14208.

6 K. Schwedtmann, S. Schulz, F. Hennersdorf, T. Strassner, E. Dmitrieva and J. J. Weigand, Angew. Chem., Int. Ed., 2015, 54, 11054-11058.

7 F. D. Henne, E.-M. Schnöckelborg, K.-O. Feldmann, J. Grunenberg, R. Wolf and J. J. Weigand, Organometallics, 2013, 32, 6674-6680.

8 See ESI ${ }^{\dagger}$.

9 F. E. Hahn and M. C. Jahnke, Angew. Chem., Int. Ed., 2008, 47, 3122-3172.

10 M. H. Holthausen, S. K. Surmiak, P. Jerabek, G. Frenking and J. J. Weigand, Angew. Chem., Int. Ed., 2013, 52, 11078-11082.

11 D. J. D. Wilson, S. A. Couchman and J. L. Dutton, Inorg. Chem., 2012, 51, 7657-7668.

12 (a) R. J. Davidson, J. J. Weigand, N. Burford, T. S. Cameron, A. Decken and U. Werner-Zwanziger, Chem. Commun., 2007, 4671-4673; (b) J. J. Weigand, N. Burford, A. Decken and A. Schulz, Eur. J. Inorg. Chem., 2007, 4868-4872; (c) M. Blättner, M. Nieger, A. Ruban, W. W. Schoeller and E. Niecke, Angew. Chem., Int. Ed., 2000, 39, 2768-2771; (d) E. Rivard, K. Huynh, A. J. Lough and I. Manners, J. Am. Chem. Soc., 2004, 126, 2286-2287; (e) N. Burford, H. A. Spinney, M. J. Ferguson and R. McDonald, Chem. Commun., 2004, 2696-2697; $(f)$ J. J. Weigand, N. Burford, D. Mahnke and A. Decken, Inorg. Chem., 2007, 46, 7689-7691.

13 H. Kessler, Angew. Chem., Int. Ed. Engl., 1970, 9, 219-235.

14 N. Burford, R. E. v. H. Spence and R. D. Rogers, J. Chem. Soc., Dalton Trans., 1990, 3611-3619.

15 P. Rovnaník, L. Kapička, J. Taraba and M. Černík, Inorg. Chem., 2004, 43, 2435-2442.

16 B. D. Ellis, C. A. Dyker, A. Decken and C. L. B. Macdonald, Chem. Commun., 2005, 1965-1967.

17 The low symmetry of 13 and the presence of the triflate anion encourage an effective quadrupole relaxation and prevents the observation of the ${ }^{1} J\left({ }^{31} \mathrm{P},{ }^{14} \mathrm{~N}\right)$ coupling. The same accounts for the more symmetric cation $\mathbf{1 4}^{+}$.

18 M. Meisel, P. Lönnecke, A.-R. Grimmer and D. Wulff-Molder, Angew. Chem., Int. Ed., 1997, 36, 1869-1870.

19 Similarly to the highly reactive intermediate $\mathbf{1 0 b}^{+}$, the tetramethyl substituted derivative $\mathbf{1 0 a}^{+}$was also observed in the reaction of 9a[OTf $]^{4}$ and 4 eq. DMAP at $\delta(\mathrm{P})=144.7 \mathrm{ppm}$. From the reaction spectra, chemical shifts as $\delta(\mathrm{P})=216.6 \mathrm{ppm}, 97.3 \mathrm{ppm}, 70.9 \mathrm{ppm}$ and $-113.2 \mathrm{ppm}$ can be assigned to $\mathbf{1 1}^{+}, \mathbf{1 4}^{+}, \mathbf{1 3}$ and $12 \mathrm{a}^{+}$, respectively. The reaction NMR is depicted in the supporting information; Details of the two polymorphs are given in the ESI ${ }^{\dagger}$.

20 Cation $\mathbf{9 \mathbf { a } ^ { \mathbf { 4 } }}$ was choosen as model system.

21 (a) A. D. Becke, J. Chem. Phys., 1993, 98, 5648-5652; (b) C. Lee, W. Yang and R. G. Parr, Phys. Rev. B: Condens. Matter Mater. Phys., 1988, 37, 785-789; (c) P. J. Stephens, E. J. Devlin, C. F. Chabalowski and M. J. Frisch, J. Phys. Chem., 1994, 98, 11623-11627; (d) S. H. Vosko, L. Wilk and M. Nusair, Can. J. Phys., 1980, 58, 1200-1211.

22 (a) T. Schwabe and S. Grimme, Phys. Chem. Chem. Phys., 2006, 8, 4398-4401; (b) S. Grimme, J. Antony, S. Ehrlich and H. Krieg, J. Chem. Phys., 2010, 132, 154104. 